\title{
Pengaruh Gaya Kepemimpinan, Motivasi dan Disiplin Kerja Terhadap Kinerja Pegawai PT. Hokinda Citralestari
}

\author{
Juniarta Rajagukguk*, Kristina Peritua Aruan, Grace Theresia Silaban, Rafida Khairani \\ Universitas Prima Indonesia, Medan \\ *Correspondence email: juniartarajagukguk1906@gmail.com
}

\begin{abstract}
Abstrak. Penelitian ini bertujuan mengetahui pengaruh gaya kepemimpinan terhadap kinerja pegawai pada PT Hokinda Citralestari, mengetahui pengaruh motivasi terhadap kinerja pegawai pada PT Hokinda Citralestari, mengetahui pengaruh disiplin kerja terhadap kinerja pegawai pada PT Hokinda Citralestari serta mengetahui pengaruh gaya kepemimpinan, motivasi dan disiplin kerja secara simultan terhadap kinerja pegawai pada PT Hokinda Citralestari. Penelitian ini adalah deskriptif kuantitatif dengan instrumen kuisioner dengan jumlah populasi seluruh pegawai PT Hokinda Citralestari sebanyak 400 orang selanjutnya dihitung rumus Slovin sehingga diperoleh sampel sebanyak 80 orang. Hasil penelitian diperoleh Nilai koefisien $t_{\text {hitung }}$ gaya kepemimpinan adalah 2,239 dan nilai $t_{\text {tabel }}$ sebesar 1,990, dimana $t_{\text {hitung }}>t_{\text {tabel }}(2,239>1,990)$ nilai sig $<0,05(0,028<0,05)$, nilai

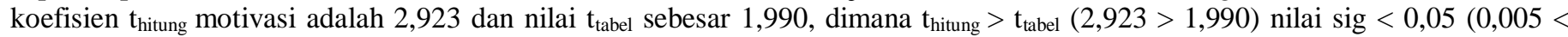
0,05), Nilai koefisien $t_{\text {hitung }}$ disiplin kerja adalah 2,148 dan nilai $t_{\text {tabel }}$ sebesar 1,990 dimana $t_{\text {hitung }}>t_{\text {tabel }}(2,148>1,990)$ nilai sig $<$

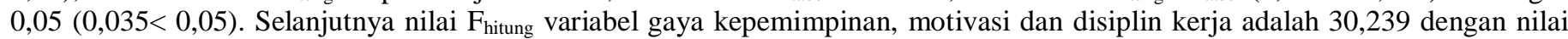
sig 0,000 dan nilai $F_{\text {tabel }}$ sebesar 2,720 dimana $F_{\text {hitung }}>F_{\text {tabel }}(30,239>2,720)$ nilai sig $<0,05(0,000<0,05)$. Nilai adjusted $R_{\text {Square }}$ yaitu 0,526 atau adjusted $\mathrm{R}^{2} \times 100 \%$ sebesar $52,60 \%$, artinya variabel bebas penelitian memberikan sumbangsih besar dalam menjelaskan tentang kinerja pegawai sebesar 52,60\% sedangkan sisanya 47,40\% dipengaruhi oleh faktor-faktor lain.
\end{abstract}

Kata kunci: Gaya Kepemimpinan; Motivasi; Disiplin Kerja; Kinerja Pegawai

\begin{abstract}
This study aims to determine the influence of leadership style on employee performance at PT Hokinda Citralestari, determine the effect of motivation on employee performance at PT Hokinda Citralestari, determine the effect of work discipline on employee performance at PT Hokinda Citralestari and to know the influence of leadership style, motivation and work discipline simultaneously on employee performance at PT Hokinda Citralestari. This research is descriptive quantitative with the instrument the questionnaire with the number of the population of all employees of PT Hokinda Citralestari as many as 400 people next calculated the Slovin formula so obtained a sample of 80 people. The results of the research obtained Value of the coefficient of $t$ leadership style is 2,239 and the value of table of 1,990, where tcount > table $(2,239>1,990)$ the value of sig $<0,05(0,028<$ $0.05)$, the coefficient value of $t_{\text {count }}$ motivation is 2,923 and the value of $t_{\text {table }}$ of 1,990 , where $t_{\text {count }}>t_{\text {table }}(2,923>1,990)$ the value of sig $<0,05(0,005<0,05)$, the Value of the coefficient $t$ work discipline is 2,148 and the value of $t_{\text {table }}$ of 1,990 where $t_{\text {count }}>t_{\text {table }}$ $(2,148>1,990)$ the value of sig <0,05 $(0,035<0,05)$. Furthermore, the value of $F_{\text {count }}$ variables of leadership style, motivation and work discipline is 30,239 with a sig value of 0.000 and the value of $F_{\text {table }}$ of 2,720 where $F_{\text {count }}>F_{\text {table }}(30,239>2,720)$ the value of sig $<0,05(0,000<0,05)$. The value of adjusted $R$-square that is 0,526 or adjusted $R 2 \times 100 \%$ of 52,60\%, meaning that the independent variables of the study provide significant contribution in explaining about the performance of employees at 52,60\% while the rest 47,40\% influenced by other factors.
\end{abstract}

Keywords: Leadership Style; Motivation; Work Discipline; Employee Performance

\section{PENDAHULUAN}

Sumber Daya Manusia (SDM) merupakan faktor terpenting dalam usaha pencapaian keberhasilan organisasi. Tantangan utama yang dihadapi oleh organisasi pada masa sekarang ini dan untuk masa yang akan datang adalah bagaimana mempersiapkan SDM yang berkualitas inovatif dan mempunyai kreatifitas tinggi. Hal tersebut menjadikan perusahaan memerlukan pegawai yang dapat mengoptimalkan kinerjanya, karena pegawai merupakan penggerak dalam menentukan keberhasilan perusahaan secara menyeluruh.

PT Hokinda Citralestari adalah perusahaan yang menghususkan diri bergerak di bidang industri kitchenware (peralatan rumah tangga) yang didirikan pada tahun 1968 dengan nama terdahulu adalah kilang kompor dengan merek Hock pada awalnya kompor hock diproduksi melalui proses yang sederhana dan umumnya dikerjakan melalui proses kerajinan tangan yang dikerjakan bersama 3 orang tenaga kerja. Kemudian pada tahun 2000 mendirikan pabrik dengan nama PT Hokinda Citralestari yang berada di jalan Orde Baru No.6A Desa Mulyorejo Sunggal.

Kinerja karyawan yakni hasil pencapaian berdasarkan kuantitas maupun kualitas yang bertujuan untuk mewujudkan target atau sasaran suatu organisasi. Berdasarkan survey awal penelitian di PT. Hokinda Citralestari melalui wawancara dengan personalia, diperoleh kinerja karyawan menurun hal ini terlihat target pekerjaan tidak tuntas sehingga harus dikerjakan besok hari, sering terjadi komplain bahkan retur produk dari konsumen karenakaryawan kurang teliti saat proses produksi, maupun saat mempacking produk sehingga terjadi cacat produk.Penurunan kinerja karyawan ini diduga terindikasi oleh faktor kepemimpinan, motivasi 
serta disiplin kerja dari masing-masing karyawan. Oleh karena itu, pimpinan perusahaan perlu mengawasi karyawan agar bekerja maksimal dengan melakukan pendekatan.

Gaya kepemimpinan adalah teknik mempengaruhi seseorang dalam berbagai kegiatannya yang dikelola untuk mencapai target yang diinginkan. Pada PT. Hokinda Citralestari terlihat gaya kepemimpinan belum efektif, dimana pemimpin dalam perusahaan memakai gaya kepemimpinan otoriter yang bersifat seluruh kekuasaan dan pengembalian keputusan hanya ada di tangan pemimpin. Sehingga dimana pimpinan terkesan menciptakan jarak dengan bawahan dimana atasan mendelegasikan perintah melalui staf, pimpinan jarang bertatap muka dan tersenyum dengan karyawan, pimpinan terlihat acuh hanya marah-marah bila karyawan ingin menemuinya. Pimpinan dalam perusahaan ini juga masih belum mampu untuk memiliki strategi yang tepat dalam melakukan perencanaan yang bertujuan untuk membuat serangkaian kebijakan dalam mengendalikan masa depan dan penetapan tujuan organisasi. Kurangnya penetapan perencanaan, pengendalian, dan pengorganisasian ini diduga menjadi penyebab mengapa kinerja kayawan menurun.

Motivasi juga di duga sebagai suatu elemen yang memberi pengaruh penting terkait peningkatan dan penurunan kinerja karyawan dalam perusahaan. Motivasi kerja karyawan pada PT. Hokinda Citralestari masih rendah hal ini terbukti dari banyaknya karyawan yang merasa kurangnya pemberian penghargaan kepada karyawan yang memiliki kinerja baik, kurangnya pemberian bonus secara merata, serta tidak adanya jaminan untuk memiliki jenjang karir yang cendrung baik.

Disiplin kerja adalah sikap dan perilaku seseorang dalam menaati atau menuruti aturan-aturan yang ada pada suatu perusahaan atau organisasi. Disiplin kerja yang ada pada PT. Hokinda Citralestari kurang terlaksananya pelayanan secara optimal dikarenakan banyak karyawan yang kurang disiplin dalam mematuhi aturan. Karyawan juga sering tidak tepat waktu untuk menyelesaikan pekerjaan yang diberikan dan karyawan dalam melaksanakan tugas cenderung tidak sesuai dengan aturan yang berlaku. Hal ini diduga disebabkan oleh suasana kerja yang kurang kondusif untuk melaksanakan tugas tersebut sehingga karyawan merasa tidak puas.

\section{Tinjauan Pustaka}

\section{Teori Pengaruh Gaya Kepemimpinan Terhadap Kinerja Karyawan}

Menurut Fahmi (2016) hasil kinerja para karyawan sangat dipengaruhi oleh seorang pemimpin. Meningkatkan kualitas kinerja pegawai memiliki pengaruh untuk menciptakan kualitas kinerja agar sesuai dengan harapan.
Menurut Suwatno dan Periansa (2018), menyatakan bahwa pemimpin yang menjalankan memimpin dengan efektif bisa membawa individu pada tujuan yang dimilikinya.Kebalikannya, jika pemimpin yang sebatas menjadi figur tanpa ada tindakan memimpin, maka cendrung memperlambat suatu kinerja organisasi. Hal tersebut dikarenakan dirinya tidak cukup berkapasitas dalam menghasilkan kinerja terbaik.

Peneliti menyimpulkan bahwa gaya kepemimpinan memiliki peran yang sangat kuat guna memotivasi serta mendorong karyawan supaya bekerja dengan loyalitas tinggi untuk mencapai hasil kinerja yang yang efektif dan maksimal.

\section{Teori Pengaruh Motivasi Terhadap Kinerja Karyawan}

Menurut Hartatik (2018), motivasi kerja yakni salah satu stimulus atau motivasi yang memunculkan semangat individu guna mewujudkan suatu tujuannya, karyawan dengan memotivasi kerja tinggi cenderung bisa membantu peningkatan kinerja perusahaan.

Menurut Riyadi (2011), dalam penelitiannya menemukan adanya hubungan yang positif dan signifikan antara motivasi terhadap kinerja karyawan. Motivasi memiliki pengaruh untuk menciptakan kenerja karyawan yang tinggi karena, karyawan yang cenderung termotivasi akan memilki semangat untuk menyelesaikan pekerjaan dengan cepat dan baik.

\section{Teori Pengaruh Disiplin Kerja Terhadap Kinerja Karyawan}

Menurut Ardana (2011), disiplin kerja merupakan suatu sikap menghormati, menghargai, patuh, dan taat terhadap peraturan-peraturan yang berlaku, baik yang tertulis maupun tidak tertulis serta sanggup menjalankannya dan tidak mengelak menerima sanksisanksinya.

Menurut Handoko (2012) disiplin merupakan kegiatan manajemen untuk menjalankan standar-standar organisasional. Kegiatan yang dilaksanakan untuk mendorong para karyawan agar mengikuti berbagai standar dan aturan, sehingga penyelewenganpenyelewengan dapat dicegah. Peneliti menyimpulkan tujuan pendisiplinan karyawan adalah menciptakan atau mempertahankan rasa hormat dan saling percaya di antara supervisi dengan bawahannya. Disiplin yang diberlakukan secara tidak tepat dapat menciptakan masalah dalam perusahaan.

\section{METODE}

\section{Tempat dan Waktu}

Penelitian ini dilakukan di PT Hokinda Citralestari, jalan Orde Baru Km. 12,5 Sei Semayang Sunggal Medan 20241. Penelitian ini membutuhkan waktu selama kurang lebih 6 bulan. 


\section{Pendekatan Penelitian}

Adapun pendekatan penelitiannya secara kuantitatif. Menurut pendapat Sugiyono (2017) memaparkan pendekatan kuantitatif yakni penelitian dengan berdasar pada filsafat positivisme, dimanfaatkan guna menjalankan penelitian pada suatu sampel ataupun populasi. Instrumen penelitian dimanfaatkan dalam pengumpulan datanya, dengan sifat analis datanya yakni kuantitatif statistic.

\section{Populasi dan Sampel}

Menurut Sugiyono (2017) populasi yakni daerah generalisasi meliputi subjek ataupun objek yang berkualitas secara berkuantitas tertentu,dimana sudah ditentukan peneliti guna dipelajari untuk berikutnya disimpulkan. Populasi pada penelitian ini adalah semua pegawai pada PT Hokinda Citralestari sebanyak 650 orang terdiri dari pegawai kantor dan marketing sebanyak 250 orang sedangkan pegawai produksi sebanyak 400 orang. Pada penelitian ini penulis membatasi populasi hanya pada pegawai produksi sebanyak 400 orang.

Sugiyono (2017) memberi defenisi kompherensif dari sampel yakni elemen dari karakteristik serta jumlah populasi tersebut. Teknik pengambilan sampelnya dengan memanfaatkan rumus Slovin. Sampel ditentukan dengan memanfaatkan teknik "simple random sampling" yaitu memilih beberapa orang pegawai secara acak diobjek penelitian sejumlah 30 guna uji reabilitas secara validitas yang didapati dari luar populasi dan sampel dan sebanyak 400 responden untuk uji sampel penelitian.

Yaitu:

$n=\frac{N}{1+\left(N x e^{2}\right)}$

Dimana:

$\mathrm{n} \quad=$ jumlah sampel

$\mathrm{N}=$ jumlah pupolasi

$\mathrm{e} \quad=$ Eror level (taraf kesalahan)

$n=\frac{400}{1+\left(400 \times 0,1^{2}\right)}$

$\mathrm{n} \quad=80$ responden

\section{Teknik Pengumpulan Data}

Metode pengumpulan data yang digunakan dalam penelitian ini adalah:

1. Kuesioner

2. Observasi

3. Dokumentasi

\section{Defenisi Operasional}

\begin{tabular}{|c|c|c|c|}
\hline Variabel & Definisi Penelitian & Indikator & Skala \\
\hline $\begin{array}{c}\text { Gaya } \\
\text { Kepemimpinan } \\
\left(X_{1}\right)\end{array}$ & $\begin{array}{l}\text { Adalah keterampilan mempengaruhi beberapa } \\
\text { individu guna terwujudnya tujuan. } \\
\text { Fahmi (2018) }\end{array}$ & $\begin{array}{l}\text { 1.Perencanaan } \\
\text { 2.Pengorganisasian } \\
\text { 3.Pemimpin } \\
\text { 4.Pengendalian } \\
\text { Umam }(2010)\end{array}$ & Likert \\
\hline $\begin{array}{l}\text { Motivasi } \\
\left(\mathrm{X}_{2}\right)\end{array}$ & $\begin{array}{l}\text { Adalah salah satu stimulus kebutuhan dakam diri } \\
\text { pegawai yang seharusnya bisa terpengaruhi } \\
\text { supaya dirinya bias melakukan interaksi dengan } \\
\text { lingkungannya. } \\
\text { Mangkunegara (2011) }\end{array}$ & $\begin{array}{l}\text { 1. Kinerja } \\
\text { 2. Penghar gaan } \\
\text { 3. Pengembangan } \\
\text { 4. Keterliba tan } \\
\text { 5. Kesempatan } \\
\text { Fauzi \& Irvan (2018) }\end{array}$ & Likert \\
\hline $\begin{array}{c}\text { Disiplin Kerja } \\
\quad\left(\mathrm{X}_{3}\right)\end{array}$ & $\begin{array}{l}\text { Adalah merupakan suatu sikap menghormati, } \\
\text { menghargai, patuh dan taat terhadap peraturan- } \\
\text { peraturan yang berlaku, baik yang tertulis maupun } \\
\text { tidak tertulis serta sanggup untuk menjalankan } \\
\text { nya dan tidak mengelak menerima sanksi- } \\
\text { sanksinya. } \\
\text { Ardana (2011) }\end{array}$ & $\begin{array}{l}\text { 1. Taat terhadap aturan waktu } \\
\text { 2. Taat terhadap aturan perusahaan } \\
\text { 3. Taat terhadap peraturan perilaku dalam } \\
\text { bekerja } \\
\text { 4. Taat terhadap peraturan lainnya } \\
\text { Sutrisno (2015) }\end{array}$ & Likert \\
\hline $\begin{array}{l}\text { Kinerja } \\
(\mathrm{Y})\end{array}$ & $\begin{array}{l}\text { Kinerja merupakan hasil pencapaian yang } \\
\text { diperoleh sebuah organisasi, yang bersifat profit } \\
\text { ataupun organisasi yang bersifat non profit selama } \\
\text { satu periode. } \\
\text { Fahmi (2016) }\end{array}$ & $\begin{array}{l}\text { 1. Kualitas } \\
\text { 2. Kuantitas } \\
\text { 3. Waktu kinerja } \\
\text { 4. Kerja sama } \\
\text { Sutrisno (2018) }\end{array}$ & Likert \\
\hline
\end{tabular}

\section{Teknik Pengolahan Data Uji Validitas}

Uji validitas sesuai paparan Ghozali (2016), dimanfaatkan guna melakukan pengukuran terkait sah ataupun tidak kuesioner yang dipakai. Kuesioner disebut valid apabila pertanyaannya bisa mengungkap hal yang hendak diukurnya.

\section{Uji Realibitas}

Realibitas sesuai paparan Ghozali (2016), yakni saranaguna melakukan pengukuran pada kuesioner sebagai indikator dari varibel. Kuesioner disebut handal ataupun reliabel jika jawaban individu akan 
pernyataannya stabil setiap waktu.

\section{Uji Asumsi Klasik \\ Uji Normalitas}

Ghozali (2016), menyatakan uji normalitas berguna melakukan pengujian terkaitapakah pada model regresi, variabel residualberdistribusi normal.Uji F serta uji t memberi asumsi jika nilai residual menyertai distribusi normal.

\section{Uji Multikoloniearitas}

Menurut Ghozali (2016), uji multikolonieritas berguna melakukan pengujian terkait apakah model regresi ada korelasi antara variabel bebas. Apabila variabel bebas saling mempunyai korelasi, maka variabel tersebut tidak ortogonal. Acuannya tolerance $\leq$ 0,10 atau sama dengan nilai $\mathrm{VIF} \geq 10$. Jika ada variabel bebas dengan nilai tolerance melebihi 0,10 nilai VIF di bawah 10, bisa didapat kesimpulan jika tidak muncul multikolonieritas.

\section{Uji Heteroskedastisitas}

Uji ini sesuai paparan Ghozali (2016), berguna melakukan pengujian terkait apakah muncul perbedaan variance pada model regresi dari residual satu pengamatan menuju pengamatan lainnya. Apabila pengamatan variance dari residual yakni sama, maka dianggap homokedastisitas, namun jika kebalikannya maka dianggap heteroskedastisitas.

\section{Uji Hipotesis}

Analisis Regresi Linier Berganda

Analisis regresi linear berganda dimanfaatkan menjadi model analisis penelitian ini. Metode ini berfungsi guna mengetahui pengaruh korelasi antara variabel independen dan variabel dependen. Rumus perhitungan persamaan regresi berganda, yakni:

$\mathbf{Y}=\mathbf{a}+\mathbf{b}_{1} \mathbf{X}_{1}+\mathbf{b}_{2} \mathbf{X}_{2}+\mathbf{b}_{3} \mathbf{X}_{3}+\mathbf{e}$

Dimana:

$\mathrm{Y}=$ Kinerja pegawai

$\mathrm{X}_{1}=$ Kepemimpinan

$\mathrm{X}_{2}=$ Motivasi

$\mathrm{X}_{3}=$ Disiplin Kerja

a $=$ Konstanta

$\mathrm{b}=$ Koefisien regresi variabel independen $\mathrm{e}=$ Kesalahan penduga (yang tak terungkap $=5 \%$ )

\section{Uji Secara Parsial (Uji t)}

Uji t (individual) menurut Ghozali (2016) pada intinya melakukan pengukuran sejauh mana pengaruh suatu variabel bebas secara individual dalam menguraikan berbagai macam variabel terikat. Hipotesis nol $\left(\mathrm{H}_{0}\right)$ yang akan dilakukan pengujian yakni apakah parameter (bi) bernilai nol, dimana:
$\mathrm{H}_{0}$ : bi = 0 (suatu variabel independent bukan penjelasan yang signifikan terhadap variabel dependen)

$\mathrm{H}_{\mathrm{a}}$ : bi $\neq 0$ (variabel tersebut yakni variabel penjelasan yang signifikan terhadap variabel dependent)

\section{Uji Secara Simultan (Uji F)}

Uji signifikan dari regresi sampel (Uji Statistik F) tidak sama dengan uji t. Uji F melakukan pengujian joint hipotesis jika $b_{1}, b_{2}$, serta $b_{3}$ secara bersamaan senilai nol, ataukah:

a. $\mathrm{H}_{0}: \mathrm{b} 1=\mathrm{b} 2=\ldots \ldots \ldots=0$

b. $\mathrm{H}_{\mathrm{a}}: \mathrm{b} 1 \neq \mathrm{b} 2=\ldots \ldots \ldots \neq 0$

Kriteria pengambilan keputusannya yakni:

$\mathrm{H}_{\mathrm{a}}$ diterima jika $\mathrm{F}_{\text {hitung }}>\mathrm{F}_{\text {tabel }}$ serta sig $<0,05$

$\mathrm{H}_{0}$ ditolak jika $\mathrm{F}_{\text {hitung }}<\mathrm{F}_{\text {tabel }}$ serta sig $>0,05$

\section{Uji Koefisien Determinasi Adjusted $\left(\mathbf{R}^{2}\right)$}

Koefisien determinasi sesuai paparan Ghozali (2016), pada dasarnya melakukan pengukuran sejauh mana kemampuan model dalam menguraikan variable dependen, dimana nilainya yakni satu serta nol. Nilai Adjusted $\mathrm{R}^{2}$ tidak selalu positif, namun juga bisa negatif.

\section{HASIL DAN PEMBAHASAN Analisis Deskriptif Penelitian Deskripsi Sampel Penelitian}

Analisis deskriptif dalam penelitian ini merupakan uraian atau penjelasan dari hasil pengumpulan data primer berupa kuesioner yang telah diisi oleh responden penelitian yang merupakan pernyataan pribadi tentang kuisioner. Adapun jumlah sampel dalam penelitian ini adalah responden yang merupakan pegawai PT Hokinda Citralestari dan bersedia menjadi sampel yaitu sebanyak 80 orang.

Adapun karakteristik responden berdasarkan jenis kelamin, umur dan tingkat pendidikan, pada tabel berikut:

Tabel 1. Karakteristik Berdasarkan Jenis Kelamin, Umur dan Tingkat Pendidikan

\begin{tabular}{ccccc}
\hline No & & Karakteristik & Jlh & $\mathbf{\%}$ \\
\hline 1 & Jenis & Laki-Laki & 35 & 43.75 \\
& Kelamin & Perempuan & 45 & 56.25 \\
& & Jumlah & $\mathbf{8 0}$ & $\mathbf{1 0 0 . 0 0}$ \\
& & $18-27$ thn & 12 & 15.00 \\
2 & Umur & $28-37$ thn & 44 & 55.00 \\
& & $>38$ thn & 24 & 30.00 \\
& & Jumlah & $\mathbf{8 0}$ & $\mathbf{1 0 0 . 0 0}$ \\
& & SMA/SMK & 42 & 52.50 \\
3 & Pendidikan & Diploma (D3) & 12 & 15.00 \\
& & Sarjana (S1) & 26 & 32.50 \\
& & Jumlah & $\mathbf{8 0}$ & $\mathbf{1 0 0 . 0 0}$ \\
\hline
\end{tabular}

Sumber: Data Penelitian Diolah (2021)

Berdasarkan data pada Tabel 1 diketahui, mayoritas responden dalam penelitian ini adalah jenis kelamin Perempuan sebanyak 45 orang (56.25\%), 
umur 28-37 tahun sebanyak 44 orang $(55.00 \%)$ dan tingkat pendidikan SMA/SMK sebanyak 42 orang $(52.50 \%)$.

\section{Uji Asumsi Klasik \\ Uji Normalitas}

Uji Normalitas bertujuan untuk menguji apakah model regresi berdistribusi normal. Untuk lebih memastikan apakah data disepanjang garis diagonal tersebut berdistribusi normal atau tidak, maka dilakukan uji Kolmogorov Smirnov $(K S)$ yakni dengan melihat data residualnya apakah distribusi normal atau tidak. Jika nilai Asym.sig (2-tailed) $>$ taraf nyata $(\alpha=0.05)$ maka data residual berdistribusi normal.

Tabel 2. Uji Normalitas One Sample Kolmogorov Smirnov Test

One-Sample Kolmogorov-Smirnov Test

\begin{tabular}{llr}
\hline & & Kinerja Pegawai \\
\hline $\mathrm{N}$ & & 80 \\
Normal Parameters & Mean & 54.6750 \\
& Std. Deviation & 4.22403 \\
Most Extreme & Absolute & .146 \\
Differences & Positive & .104 \\
& Negative & -.146 \\
Test Statistic & .146 \\
Asymp. Sig. (2-tailed) & $.100^{\mathrm{b}}$ \\
\hline a. Test distribution is Normal. \\
b. Calculated from data. \\
s. Lilliefors Significance Correction.
\end{tabular}

Sumber: Data Penelitian Diolah SPSS 24.0 (2021)

Berdasarkan data pada tabel 2, besar nilai signifikasi kolmogrov Smirnov sebesar 0,270 maka dapat disimpulkan data terdistribusi secara normal, dimana nilai signifikasinya lebih besar dari $0,05(\mathrm{p}=0,100$ > $0,05)$.

\section{Uji Multikolinieritas}

Gejala multikolinieritas dapat dilihat dari besarnya nilai Tolerance dan VIF (Variance Inflation Factor). Nilai yang dipakai untuk Tolerance $>0,10$ dan VIF $<1,0$ maka tidak terjadi multikolinieritas. Nilai Tolerance dan VIF (Variance Inflation Factor) pada Tabel berikut:

Tabel 3. Uji Multikolinieritas Coefficients $^{\mathbf{a}}$

\begin{tabular}{lcc}
\hline & \multicolumn{2}{c}{ Collinearity Statistics } \\
\cline { 2 - 3 } Model & Tolerance & VIF \\
\hline 1 (Constant) & & \\
Gaya Kepmpnn & .484 & 2.066 \\
\hline Disiplin Kerja & .471 & 2.123 \\
\hline Motivasi Kerja & .424 & 2.360 \\
\hline
\end{tabular}

a. Dependent Variable: Kinerja Pegawai

Sumber: Data Penelitian Diolah SPSS 24.0 (2021)
Berdasarkan data pada Tabel 3 memperlihatkan semua nilai variabel independen memiliki nilai Tolerance < 0,10 dan VIF > 1,00 dimana dengan nilai Tolerance masing-masing sebesar $(0.484 ; 471$ dan $424>0,10)$ sedangkan nilai VIF dari masing-masing sebesar (2.066; 2.123 dan $2.360>1,00$ ) sehingga hal ini berarti dalam penelitian ini tidak terjadi multikolinieritas.

\section{Uji Heteroskedastisitas}

Uji heteroskedastisitas dapat dilakukan dengan grafik dan analisis statistic berupa uji scatterplot. Melalui analisis grafik, suatu model regresi dianggap tidak terjadi heteros-kedastisitas jika titik-titik menyebar secara acak dan tidak membentuk suatu pola tertentu yang jelas serta tersebar di atas maupun di bawah angka nol pada sumbu $\mathrm{Y}$ seperti yang terlihat pada Gambar 1 berikut.

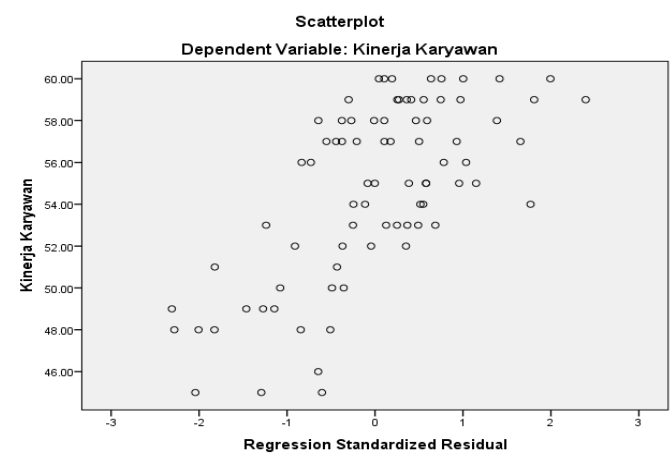

Gambar 1. Pengujian Heteroskedastisitas. Sumber: Data Penelitian Diolah SPSS 24.0 (2021)

Berdasarkan data pada Gambar 1 diketahui bahwa titik menyebar secara acak dan tidak membentuk suatu pola tertentu yang jelas serta tersebar baik di atas maupun di bawah angka nol pada sumbu Y. Pengujian ini menunjukkan bahwa model regresi ini bebas dari masalah heteroskedastisitas, dengan perkataan lain bahwa variabel-variabel yang akan diuji dalam penelitian ini bersifat homoskedastisitas.

\section{Regresi Linier Berganda}

Regresi linier berganda bertujuan menghitung besarnya pengaruh dua atau lebih variabel bebas terhadap satu variabel terikat dan memprediksi variabel terikat dengan menggunakan dua atau lebih variabel bebas. Rumus analisis regresi berganda, berikut:

Tabel 4. Regresi Linier Berganda

\begin{tabular}{|c|c|c|c|c|c|}
\hline \multicolumn{6}{|c|}{ Coefficients $^{\mathrm{a}}$} \\
\hline \multirow[b]{2}{*}{ Model } & \multicolumn{2}{|c|}{$\begin{array}{l}\text { Unstandar dized } \\
\text { Coefficients }\end{array}$} & \multirow{2}{*}{$\begin{array}{c}\begin{array}{c}\text { Standardized } \\
\text { Coefficients }\end{array} \\
\text { Beta }\end{array}$} & \multicolumn{2}{|c|}{$\begin{array}{c}\text { Collinearity } \\
\text { Statistics }\end{array}$} \\
\hline & $\mathrm{B}$ & Std. Error & & Tolerance & VIF \\
\hline 1 (Constant) & 9.217 & 4.800 & & & \\
\hline Gaya Kepemipinan & .233 & .104 & .249 & .484 & 2.066 \\
\hline Disiplin Kerja & .287 & .098 & .330 & .471 & 2.123 \\
\hline Motivasi Kerja & .257 & .120 & .256 & .424 & 2.360 \\
\hline
\end{tabular}


Berdasarkan data pada tabel 4 diperoleh regresi linier berganda berikut:

\section{$Y=9,217+0,233 X_{1}+0,287 X_{2}+0,257 X_{3}$}

Interpretasi dari persamaan regresi linier berganda adalah:

1. Jika segala sesuatu pada masing-masing variabel bebas dianggap nol maka nilai kinerja pegawai (Y) adalah sebesar 9,217.

2. Jika terjadi peningkatan pada gaya kepemimpinan 1 poin, maka kinerja pegawai (Y) akan meningkat sebesar 0,233.

3. Jika terjadi peningkatan pada motivasi sebesar 1 poin, maka kinerja pegawai (Y) akan meningkat sebesar 0,287 .

4. Jika terjadi peningkatan pada disiplin kerja sebesar 1 poin, maka kinerja pegawai (Y) akan meningkat sebesar 0,257. sebesarlpoin, maka Kinerja Pegawai pegawai(Y) akan meningkat sebesar 0,681.

\section{Uji Hipotesis}

\section{Uji Signifikan Parsial (Uji t)}

Uji-t (uji parsial) dilakukan untuk melihat secara individual pengaruh secara positif dan signifikan dari variabel bebas terhadap variabel terikat, dimana variabel bebas yaitu gaya kepemimpinan, motivasi dan disiplin kerja terhadap kinerja pegawai PT Hokinda Citralestari, berikut:

Tabel 5. Nilai Coefficients Coefficients ${ }^{a}$

\begin{tabular}{lcccc}
\hline & & \multicolumn{3}{c}{ Collinearity Statistics } \\
\cline { 3 - 5 } Model & $\mathbf{t}$ & Sig. & Tole rance & VIF \\
\hline 1 (Constant) & 1.920 & .059 & & \\
Gaya Kepmpnn & 2.239 & .028 & .484 & 2.066 \\
$\quad$ Disiplin Kerja & 2.923 & .005 & .471 & 2.123 \\
$\quad$ Motivasi & 2.148 & .035 & .424 & 2.360 \\
$\quad$ Kerja & & & & \\
\hline
\end{tabular}

a. Dependent Variable: Kinerja Pegawai

Sumber: Data Penelitian Diolah SPSS 24.0 (2021)

Berdasarkan data pada tabel 5 diketahui nilai coefficients secara parsial dari masing-masing variabel, sebagai berikut:

1. Variabel Gaya Kepemimpinan $\left(\mathrm{X}_{1}\right)$

Nilai thitung variabel Gaya kepemimpinan adalah 2,239 dan nilai $t_{\text {tabel }}$ sebesar 1,990 (rumus Excel $=\operatorname{TINV}(0.05,80)$ maka nilai $\mathrm{t}_{\text {hitung }}>\mathrm{t}_{\text {tabel }}(2,239>$ 1,990) dan nilai sig lebih kecil dari $0,05(0,028<$ $0,05)$, dapat disimpulkan Gaya kepemimpinan secara parsial berpengaruh signifikan terhadap Kinerja pegawai PT Hokinda Citralestari.

2. Variabel Motivasi kerja $\left(\mathrm{X}_{2}\right)$

Nilai thitung variabel Motivasi Kerja adalah 2,293 dan nilai $t_{\text {tabel }}$ sebesar 1,990 (rumus Excel $=\operatorname{TINV}(0.05,80)$ maka nilai $\mathrm{t}_{\text {hitung }}>\mathrm{t}_{\text {tabel }}(2,393>$ 1,990) dan nilai sig lebih kecil dari $0,05(0,005<$
0,05), dapat disimpulkan Motivasi secara parsial berpengaruh signifikan terhadap Kinerja pegawai PT Hokinda Citralestari

3. Variabel Disiplin kerja $\left(X_{3}\right)$

Nilai thitung variabel Disiplin Kerja adalah 2,148 dan nilai $t_{\text {tabel }}$ sebesar 1,990 (rumus Excel $=\operatorname{TINV}(0.05,80)$ maka nilai $\mathrm{t}_{\text {hitung }}>\mathrm{t}_{\text {tabel }}(2,148>$ 1,990) dan nilai sig lebih kecil dari $0,05(0,035<$ $0,05)$ dapat disimpulkan Disiplin kerja secara parsial berpengaruh signifikan terhadap Kinerja pegawai PT Hokinda Citralestari.

4. Variabel Dominan Mempengaruhi

Nilai thitung variabel Disiplin kerja adalah 2,293 dan nilai $t_{\text {tabel }}$ sebesar 1,990 (rumus Excel $=\operatorname{TINV}(0.05,80)$ maka nilai $\mathrm{t}_{\text {hitung }}>\mathrm{t}_{\text {tabel }}(2,293>$ 1,990) dan nilai sig lebih kecil dari $0,05(0,005<$ $0,05)$ sehingga dapat disimpulkan disiplin kerja secara parsial berpengaruh signifikan dan merupakan variabel dominan terhadap Kinerja pegawai PT Hokinda Citralestari.

\section{Uji Signifikan Simultan (Uji F)}

Uji F (uji simultan) dilakukan untuk melihat pengaruh secara simultan/ serempak variabel bebas terhadap variabel terikat. Adapun cara yang digunakan adalah dengan melihat level of significant $(=0,05)$ lebih kecil dari 0,05 (sig < 0.05$)$, berikut:

Tabel 6. Uji Annova (Simultan)

\begin{tabular}{lrrrrr}
\multicolumn{6}{c}{ ANOVA $^{\mathbf{a}}$} \\
\hline Model & Sum of Squares & df & Mean Square & F & Sig. \\
\hline 1 Regression & 766.992 & 3 & 255.664 & 30.239 & $.000^{\mathrm{b}}$ \\
Residual & 642.558 & 76 & 8.455 & \\
$\quad$ Total & 1409.550 & 79 & & & \\
\hline a. Dependent Variable: Kinerja Pegawai & & \\
b. Predictors: (Constant), Motivasi, Gaya Kepmpnn, Disiplin Kerja \\
Sumber: Data Penelitian Diolah SPSS 24.0 (2021)
\end{tabular}

Sumber: Data Penelitian Diolah SPSS 24.0 (2021)

Berdasarkan data pada tabel 6 nilai $\mathrm{F}_{\text {hitung }}$ sebesar 30,239 dan $\mathrm{F}_{\text {tabel }}$ sebesar 2,720 (rumus Excel $=$ FINV $(0.05,3,80)$ maka nilai $F_{\text {hitung }}>t_{\text {tabel }}(30,239>2,720)$, dan nilai sig lebih kecil dari $0,05(0,000<0,05)$, dapat disimpulkan gaya kepemimpinan, motivasi dan disiplin kerja secara simultan berpengaruh signifikan terhadap kinerja pegawai PT Hokinda Citralestari.

\section{Uji Koefisien Determinasi $\left(R^{2}\right)$}

Pengujian koefisien determinasi $\left(\mathrm{R}^{2}\right)$ digunakan untuk mengukur proporsi atau persentase kemampuan model dalam menjelaskan variabel terikat yang berkisar antara nol sampai satu $\left(0 \leq \mathrm{R}^{2} \leq 1\right)$. Jika $\mathrm{R}^{2}$ semakin besar (mendekati satu), maka dapat dikatakan bahwa pengaruh variabel bebas (X) adalah besar terhadap variabel terikat $(\mathrm{Y})$, artinya model yang digunakan semakin kuat untuk menerangkan kemampuan variabel bebas dalam menjelaskan variabel terikat dan demikian sebaliknya, terlihat pada Tabel 15 berikut: 
Tabel 7. Model Summary Goodness of Fit $\left(\mathrm{R}^{2}\right)$ Model Summary ${ }^{\mathrm{b}}$

\begin{tabular}{llrrrr}
\hline \multicolumn{7}{c}{ Model Summary } \\
Model & R & R Square & $\begin{array}{c}\text { Adjus ted R } \\
\text { Square }\end{array}$ & $\begin{array}{l}\text { Std. Error of } \\
\text { the Estimate }\end{array}$ & $\begin{array}{l}\text { Durbin- } \\
\text { Watson }\end{array}$ \\
\hline 1 & $.738^{\mathrm{a}}$ & .544 & .526 & 2.90770 & 1.998 \\
\hline
\end{tabular}

a. Predictors: (Constant), Motivasi Kerja, Gaya Kepmpnn, Disiplin Kerja

b. Dependent Variable: Kinerja Pegawai

Sumber: Data Penelitian Diolah SPSS 24.0 (2021)

Berdasarkan data pada tabel 7 , Nilai adjusted $R_{\text {Square yaitu } 0,526}$ atau adjusted $\mathrm{R}^{2}$ x $100 \%$ sebesar $52,60 \%$, artinya variabel bebas penelitian berupa gaya kepemimpinan, motivasi dan disiplin kerja memberikan sumbangsih besar dalam menjelaskan tentang kinerja pegawai sebesar $52,60 \%$ sedangkan sisanya $47,40 \%$ dipengaruhi oleh faktor-faktor lain di luar penelitian ini seperti variabel budaya organisasi, kompetensi, kompensasi, faktor personal dan faktor situasi, kebijakan pemerintah dan situasi perekonomian nasional.

\section{SIMPULAN}

Berdasarkan hasil penelitian di atas, dapat diambil kesimpulan antara lain:

1. Hasil uji regresi linier berganda diperoleh persamaan linier yaitu $Y=9,217+0,233 X_{1}+0,287 X_{2}+0,257 X_{3}$

2. Gaya kepemimpinan secara parsial berpengaruh signifikan Terhadap Kinerja karyawan dengan nilai sig $<0,05(0,009<0,05)$, motivasi secara parsial berpengaruh signifikan terhadap Kinerja karyawan dan merupakan variabel dominan yang mempengaruhi Kinerja karyawan dimana nilai dengan nilai sig $<0,05(0,000<0,05)$ dan disiplin kerja secara parsial berpengaruh signifikan Terhadap Kinerja karyawan dengan nilai sig < 0,05 $(0,019<0,05)$

3. Gaya kepemimpinan, Motivsai dan Disiplin kerja secara simultan berpengaruh signifikan terhadap Kinerja karyawan dengan nilai sig $<0,05(0,000<$ $0,05)$.

4. Nilai adjusted $R_{\text {Square }}$ yaitu 0,526 atau adjusted $\mathrm{R}^{2} \mathrm{x}$ $100 \%$ sebesar $52,60 \%$, artinya variabel bebas penelitian berupa gaya kepemimpinan, motivasi dan disiplin kerja memberikan sumbangsih besar dalam menjelaskan tentang kinerja pegawai sebesar 52,60\% sedangkan sisanya $47,40 \%$ dipengaruhi oleh faktorfaktor lain di luar penelitian.

\section{DAFTAR PUSTAKA}

Ardana, I Komang dkk. 2014. Manajemen Sumber Daya Manusia. Denpasar: Graha Ilmu

Edy Sutrisno 2018. Budaya organisasi. Edisi ke-4. ISBN 978-602-8730-02-0. Jakarta: Kencana. Prenadamedia Grup. Bandung: Alfabeta CV

Fahmi, Irham. 2016. Manajemen Sumber Daya Manusia Teori dan Aplikasi. Bandung: Alfabeta
Fahmi, Irham. 2018. Pengantar Manajemen Keuangan. Bandung: Alfabeta

Fauzi dan Irvan.2018.Manajemen Sumber Daya manusia. Teori dan aplikasi. Bandung: Alfabeta CV

Handoko, T. Hani. 2012. Manajemen Personalia dan Sumber Daya Manusia. Yogyakarta. BPFE

Hartatik, Puji, Indah , 2018, Sumber Daya Manusia, Jogjakarta: Laksana

Ghozali, Imam. 2016. Aplikasi Analisis Multivariate Dengan Program SPSS. Semarang: Badan Penerbit Universitas Diponegoro.

Khaerul. Umam. 2010. Perilaku Organisasi. Bandung: Pustaka Setia

Mangkunegara. 2011. Manajemen Sumber Daya Perusahaan. PT . Remaja Rosdakarya. Bandung

Riyadi, S., 2011. Pengaruh kompensasi finansial, gaya kepemimpinan, dan motivasi kerja terhadap kinerja karyawan pada perusahaan manufaktur di Jawa Timur. Jurnal manajemen dan kewirausahaan, 13(1), pp.40-45

Sugiyono. 2017. Metode Penelitian Manajemen, Cetakan keempat. Bandung: Alfabeta.

Sutrisno, Edy. 2015. Manajemen Sumber Daya Manusia(Cetakan ke tujuh). Jakarta: Kencana Prenada Media Group

Suwatno dan Donni Juni Priansa. 2018. Manajemen Sumber Daya Manusia dalam Organisasi public dan Bisnis, Bandung: Alfabeta 